\title{
The intergenerational foundations of class voting: social mobility and electoral choice in Western Europe
}

\author{
Giuseppe Ciccolini \\ EURopeAn University Institute \\ Juho Härkönen \\ European University Institute \\ Draft version: September 2021
}

\begin{abstract}
Scholarly explanations of the survival of left parties and the upsurge in mainstream politics discontent often refer to voters' intergenerational mobility resulting from the post-industrial transition. As the occupational structure evolves, voters across generations are exposed to heterogenous life chances, and the social elevator progressively alters class voting patterns. Yet empirical evidence for the electoral implications of social ascent and decline as well as their reasons is mixed at best - likely because most empirical studies seek for homogenous average mobility effects. To address this limitation, we analyse the diverse consequences of mobility across social groups in a quasi-descriptive fashion by applying a cutting-edge ANOVA-based OLS model. Contrarily to prior studies, this approach allows us to identify class-specific mobility effects on voting (ceteris paribus), consistently with theory. Our analyses draw on individual-level detailed information on both intergenerational social mobility and political behaviour from the European Social Survey (rounds 1-9) across 19 Western European countries. Although scholarly accounts on the consequences of social mobility averagely find little to no support in our analyses, we do observe some significant and substantial class-specific effects of both social ascent and descent on voting choice.
\end{abstract}

\section{Introduction}

The transition to post-industrialism and the subsequent transformations of the occupational structure are deemed to be responsible for major changes in the European political landscape. Traditional patterns in class voting, with lower classes disproportionately supporting the left and higher ones the right, have been shaken by two consecutive phenomena. Firstly, the emergence of a new upper and middle class, mainly consisting of high-skilled service workers, has led to a reconfiguration of the traditional electoral base of left parties (Kitschelt 1994). This has been critical for the survival of the left at a time when the size of the working class - its original electoral base - was shrinking. Secondly, the following slowdown in the expansion of the said new class, coupled with cyclical or even structural

$\bowtie$ Correspondence should be addressed to: giuseppe.ciccolini@eui.eu Please do not cite or distribute without permission of the authors.

The code utilized to produce the results will be available after publication. Data from the European Social Survey are publicly available on the study website upon registration. 
economic downturn, has been creating room for popular discontent, which radical parties capitalize on (Bonikowski 2017; Jackson and Grusky 2018). Consequently, traditional post-war patterns in class voting have been altered by historical trends in intergenerational mobility.

Yet, it is unclear the extent to which these political phenomena result from the dynamics of social ascent and decline. Research has majorly focused on voters' own occupational class (Oesch and Rennwald 2018) and the characteristics of the latter (Kitschelt and Rehm 2014), while evidence about mobility effects on voting is more scattered and partly inconclusive. On the one hand, the argument that upwardly mobile citizens disproportionately support inequality reduction and cultural progressivism is not corroborated by empirical evidence (Abramson and Books 1971; Alesina and La Ferrara 2005; Ares 2020; Breen 2001; Corneo and Grüner 2002; Jaime-Castillo and MarquésPerales 2019; Piketty 1995; Siedler and Sonnenberg 2012). On the other, although the claim that dissatisfaction stemming from downward mobility favours radical voting has received some support (Daenekindt et al. 2018; Mayer 2002; Peugny 2006), it remains unclear whether this is most relevant for parties on the left or the right (Kurer and van Staalduinen 2020; Mitrea et al. 2020) and why (Paskov et al. 2020; Tolsma et al. 2009).

We consider this limitation to stem from the following inconsistency. The most relevant theoretical discussions around the electoral consequences of social mobility raise expectations about class-specific heterogenous effects. Therefore, mobility is expected to influence voting among certain social classes but not among others - or otherwise differently. Yet most empirical research relies on simplistic methods that can only identify a single average upward or downward mobility effect for all social groups. Still more, even if the focus were on the average consequence of a social trajectory, scholars have likely fallen short from identifying it so far. This is because they are commonly left with an uncomfortable trade-off (Blalock 1966, 1967): either modelling the association between mobility and voting without controlling for family background, thus possibly incurring in omitted variable bias, or refraining from using OLS and settling for odder methods (Hendrickx et al. 1993; Sobel 1981, 1985) that are liable to criticism (Fosse and Pfeffer 2021).

The aim of the present study is to reconcile theory and empirical applications and advance scholarly knowledge on the relation between mobility and voting. Differently from prior studies, we contribute to the extant debate by analysing the - potentially diverse - electoral implications of mobility across different social classes, consistently with the theoretical expectations drawn from the literature. To do so, we adopt an innovative strategy allowing us to identify class-specific mobility effects, thus overcoming the said limitations of previous analyses. More precisely, we account for the horizontal cleavages in the social structure (Oesch 2006a,b) and model mobility effects by means of the newly developed Mobility Contrast Model (Luo 2021). Based on ANOVA, MCM is a flexible tool to study the heterogenous associations between mobility and voting across groups, while holding voters' class 
and family background (among other factors) constant, though without departing from the well-known framework of OLS. Empirically, we leverage data from the European Social Survey (rounds 1-9) on voters' electoral choice and political attitudes across 19 Western European countries. All in all, our strategy enables us to draw a less simplistic picture of the intergenerational foundations of class voting in Europe.

\section{Literature review}

\section{Voting in the golden age of capitalism}

The two and a half decades following the Second World War have been described as the golden age of capitalism (Crafts and Giovanni 1996; Marglin and Schor 1992). In advanced European countries, this era was characterized by robust economic growth, full employment, and the expansion of the welfare state. In addition, these phenomena were accompanied and sustained by educational expansion. Economic development both demanded and resulted from the creation of new jobs, namely in the segment of the professional, administrative and managerial employment, thus resulting in the emergence of a new salaried upper and middle class (Breen 2004; Erikson and Goldthorpe 1992). ${ }^{1}$ Although these transformations initially benefited men mostly, women later joined this trend too (Bukodi and Paskov 2020). Thus, the occupational structure of society as a whole was altered. Most members of this new class were of modest origins. Hence, they benefited from this unexpected external shock and managed to access a higher class position than their parents (Lipset 1959). Upward mobility was widespread in all European countries for the generations born in the first half of the $19^{\text {th }}$ century.

Three strands of literature theorize the possible electoral consequences of this dramatic change in the occupational structure. At early times, Goldthorpe (1982) speculated that right-wing parties would be the main beneficiaries of the expansion of the new class. This is because its members work in occupations involving the exercise of authority or of specialized knowledge, featuring higher level of advantage with respect to lower grade positions. Therefore, they would have an interest in maintaining the status quo and securing their position (and the one of their children), thus making a possible alliance with the working class unlikely.

Nonetheless, empirical evidence seems to partly contradict this expectation, which brings us to the following two strands. Kitschelt (1994), Kriesi (1998) and Müller (1999) observe that a significant part of the new upper and middle class has become a firm supporter of left parties - a pattern that historically goes on well beyond the golden age of capitalism. Therefore, the left was able to survive

\footnotetext{
${ }^{1}$ Scholars tend to use the terms upper and middle class (or either of the two) in a rather scattered and even loose way - reflecting a longstanding and still unsettled debate (Schmoller 1897). Therefore, we do the same in this section, and defer the usage of a more appropriate denomination to the remaining of the paper.
} 
to the later decline in industrial working-class employment by progressively co-opting new voters from the said group, which eventually became its core constituency (Gingrich and Häusermann 2015; Oesch and Rennwald 2018). This alignment occurred for economic considerations, as the new class turned to be a fervent supporter of the welfare state, but also thanks to the emergence of a new cultural dimension, where the left rapidly positioned itself on the liberal side. From a different perspective, Inglehart (1977) also makes a similar argument. The increase in economic opportunities and the rising living standards following WWII caused a shift in citizens' value. Materialist considerations gave the way to post-material ones, with an increasing support for cultural liberalism.

All in all, this strand of scholarship sees left parties as the main beneficiary of occupational upgrading. Two sets of arguments provide an explanation for this electoral alignment. The first one considers occupational characteristics (Kitschelt and Rehm 2014). A considerable portion of the said new middle and upper class is employed in occupations that require inter-personal interactions. Through these interactions, employees experience the uniqueness of humankind, ultimately fostering egalitarian and solidaristic values. Nonetheless, stable occupational characteristics per se are insufficient to explain, namely, why the upper and middle class aligned to the left only in the second part of the $20^{\text {th }}$ century, that is only after its expansion. The second one, which is the most salient within the context of the present paper, regards social mobility. Because this new class is mostly composed of socially ascending individuals, as written earlier, it may be that upward mobility per se leads to left voting. More specifically, within the historical context we are dealing with, this relation could stem from the very engine of ascension. Because a significant part of the jobs of the new class are in the public sector or somewhat related to the welfare state, it is plausible that the latter has to some extent created its own support base, by granting social ascent to its workers (Heath 1991; McAdams 1987).

The thesis of a new leftist upper and middle class has become relatively dominant in scholarly literature. Nonetheless, the connection between upward mobility and left voting lacks empirical support. ${ }^{2}$ Some studies do not find evidence for a positive relation between the former and pro-redistribution preferences (Jaime-Castillo and Marqués-Perales 2019), cultural liberalism (Paskov et al. 2020), or voting for left parties (Kurer and van Staalduinen 2020). ${ }^{3}$ Even more strikingly, other studies find just the opposite: upward mobility appears to increase economic conservatism (Alesina and La Ferrara 2005; Ares 2020; Corneo and Grüner 2002; Piketty 1995; Siedler and Sonnenberg 2012) and right-wing voting (Abramson and Books 1971; Breen 2001), at least among some groups (Mayer and Perrineau 1992). Research on the prospect of mobility reaches similar conclusions (Alesina et al. 2018; Benabou and Ok 2001; McCall and Manza 2011). This relation may have two justifications. Firstly, upwardly

\footnotetext{
${ }^{2}$ As an exception, Kurer and van Staalduinen (2020) do find a positive relation with cultural liberalism.

${ }^{3}$ For the purpose of this review, we combine studies on social class and income mobility, intergenerational and life-course one, as the underlying mechanisms to explain voting behaviour are rather similar. In the same vein, we do not include subjective mobility.
} 
mobile people may overestimate the role of talent and hard work - rather than predetermined characteristics - for their life success, therefore strengthening the belief that inequalities are natural and should be considered acceptable because resulting from meritocracy. Secondly, upwardly mobile people may pursue self-interest and oppose redistributive policies that are likely to increase social fluidity and therefore thwart their efforts to secure their children's social position.

\section{Social descent and radicalism}

Scholars agree that the aforementioned era of widespread social ascent has come to an end (Breen 2004; Breen and Müller 2020; Bukodi and Goldthorpe 2018). Demand for high-skilled jobs is still increasing, as a result of as skill-biased technological change (Berman et al. 1998), but it does so at a decreasing rate (Bukodi et al. 2020). In other words, although there is constantly "more room at the top", to use the mobility research jargon, its increase has become unsustainable in the long run. Furthermore, some authors argue that the job market has been polarizing, at the detriment of middle-skilled routine occupations (Autor and Dorn 2013; Kurer and Palier 2019), at least in some national contexts (Oesch and Piccitto 2019). These two trends have a straightforward implication. A growing part of population has not succeeded in attaining their parents' position, and therefore has fallen behind. Therefore, although downward mobility has virtually always existed, it is becoming a further common experience since the mid-1970s.

Scholars have inquired whether downward mobility may engender political dissatisfaction and lead to radical voting. This expectation echoes a larger debate on the causes of radical (and populist) voting. The latter is interpreted in at least two (complementary) ways. A first interpretation regards (individual) loss (Jackson and Grusky 2018). Here again, a distinction could be made. Absolute loss, such as a drop in income or dismissal, appears to be more relevant for radical left parties (Gidron and Mijs 2019; Margalit 2019). Relative or even relational loss, such as the fading away of wage increase prospects or the increasing (decreasing) gap from highly (lowly) socially valued groups, is observed to be especially favourable for radical right parties and more generally culturally conservative politics (Bonikowski 2017; Burgoon et al. 2019; Gidron and Hall 2017; Green et al. 2021; Green and Shorrocks 2021; Im et al. 2019; Kurer 2020). The second interpretation concerns societal pessimism and - more precisely - a deep feeling of nostalgia (Gest et al. 2018; Steenvoorden and Harteveld 2018). This is likely to be activated notably in case of local economic downturn (Baccini and Sattler 2021; Colantone and Stanig 2018a,b; Fetzer 2019).

These two interpretations extend to downward mobility research too. On the one hand, parents represent a heavily influential reference for individuals across different life domains (Checchi 2006; Cohen 1987; Dustmann 2004; Johnson 2002). Thus, parental class represents a clear target that should be - at least - achieved, and individuals develop expectations based on their parents' situation since 
childhood and adolescence (Hyman 1942). What's more, social rigidities make such expectation rather reasonable (Hill and Duncan 1987). This is particularly salient for those who experience a downward trajectory. Negative evaluations may engender frustration, resentment, and desire for radical change. On the other, among downwardly mobile individuals, the parents-offspring comparison may lead to develop a sense of nostalgia for a more prosperous past and turn to parties that promise to restore it.

Extant evidence for a relation between downward mobility and radical voting is promising. The former is found to be associated with political distrust (Daenekindt et al. 2018). Studies confirm that is it is influential for voting for radical parties on both sides of the political spectrum (Kurer and van Staalduinen 2020; Mitrea et al. 2020), albeit mainly on the right (Mayer 2002; Peugny 2006). Nonetheless, the controversy over whether social descent is more relevant for either left or right radical voting (or simply both) remains unsettled. Research shows a positive relation with pro-redistribution attitudes (Alesina and La Ferrara 2005; Ares 2020; Siedler and Sonnenberg 2012), which would lend further support for the first hypothesis. Also, one would reasonably expect downward mobility to be associated with important predictors of radical right voting, so as to corroborate the second hypothesis. In this respect, evidence on immigration attitudes is mixed. Some scholars find a positive effect (Kurer and van Staalduinen 2020), others do not find it (Tolsma et al. 2009), while others observe conflicting findings depending on the national context (Paskov et al. 2020).

\section{Hypotheses}

Based on the foregoing discussion we formulate two main sets of hypotheses. Our first focus is on upward mobility. Because there is a widespread belief that occupational upgrading has granted continuing support for the left despite deindustrialization, we hypothesize that upward mobility increases left voting, namely for the centre-left (i.e., including both social-democratic and green parties) (H1). To be as much consistent as possible with the argument of Kitschelt (1994), Kriesi (1998), Müller (1999), and following scholars, we also acknowledge that such upward effect should be expected only among the new upper and middle class and, more specifically, among a precise segment within it: employees in the service sector or, more specifically, in occupations involving inter-personal relations (H1a). These have emerged as the main support base of left parties, while their peers on the same social ladder though involved in a different work logic (i.e., a technical or organizational one) experience upward mobility outside the context of the welfare state and therefore turn to centre-right parties (H1b). Afterwards, we wish to also test the argument that upward mobility spurs economic conservatism, and therefore hypothesize that there is a positive relation between the former and right voting, especially for moderate parties (H2).

Finally, we turn to downward mobility and hypothesize that it should increase radical voting (H3). 
Based on the literature, we cannot develop clear expectations on whether it is supposed to favour radical left $(\mathrm{H} 3 \mathrm{a})$ or radical right voting $(\mathrm{H} 3 \mathrm{~b})$. Therefore, we separately test both arguments. In this respect, we are keen to verify whether the well-known widespread support for the radical right among the working class may be at least partly the result of downward mobility. This may arise from the above-mentioned phenomenon of job polarization, as middle-skilled routine occupations progressively disappear and workers who do not adapt fall into the lower ranks. Thus, we hypothesize that downward mobility to the working class increases radical right voting $(\mathrm{H} 3 \mathrm{c})$.

\section{Methods}

\section{Data and sample}

Our analysis relies on data from the European Social Survey (ESS), a cross-country study at the European level conducted on a two-year basis. ESS is the most suitable source for the purpose of our study, since it gathers individual data on electoral choice at each last election, as well as detailed socioeconomic characteristics (employment status, occupation, etc.) on voters and, uncommonly, their parents. ${ }^{4}$ By combining all the nine survey rounds of ESS, we analyse data covering elections from the early 2000 over almost twenty years. Our main analysis covers 19 Western European countries. We restrict our interest to voters aged 30 or more - as it is common in mobility research to ensure that individuals' class has stabilised - who either actively work, or are unemployed (but have ever worked), or are retired. We also include non-voters in supplementary analyses.

\section{Identification strategy}

We regress voting choice - i.e., our main dependent variable - using a linear probability model, as the latter outperforms logistic regression in case of quasi-complete separation. ${ }^{5}$ To test our hypotheses, we leverage on the cutting-edge Mobility Contrast Model (Luo 2021). This method operationalises social mobility as the interaction - in both the theoretical and statistical sense - of individuals' social class (i.e., destination) and parental class (i.e., origin). Additionally, it conceives mobility effects on a given outcome as the difference - i.e. the contrast - between the average outcome for a given mobility combination (e.g. middle-class individuals coming from a working-class background) and the average outcome for the immobile individuals among the very same parental class (peers from a working-

\footnotetext{
${ }^{4}$ Detailed ISCO code information on parents' occupations has been collected in the framework of the ESS-DEVO project (Ganzeboom 2013). Its coverage extends up to the $5^{\text {th }}$ round. In the absence of detailed information afterwards, we impute parental class from the $6^{\text {th }}$ round onward based on a rougher variable asked throughout the whole survey. As a robustness check, we only analyse the original non-imputed survey rounds.

'Some combinations of respondents' and parents' class feature zero (or close to zero) voters of radical left or right parties. Thus, such combinations perfectly predict the outcome and maximum likelihood estimates do not exist (Albert and Anderson 1984).
} 
class background who have not experienced mobility), once origin and destination main effects (the average outcome among, respectively, all the middle-class individuals and all the individuals born in a working-class background) are taken into account. ${ }^{6}$ More formally, this method draws on the following an ANOVA-based OLS regression model:

$$
E\left(Y_{o d}\right)=\mu+\alpha_{o}+\beta_{d}+\delta_{o d}+\gamma \mathbf{X}
$$

where $E\left(Y_{o d}\right)$ denotes the expected value of the outcome $Y$ for the oth origin in the $d$ th destination; $\mu$ is the grand mean (i.e., the average outcome if all origin-destination combinations had equal size); the main effects $\alpha_{o}$ and $\beta_{d}$ are respectively the origin and destination effects; $\delta_{o d}$ are the interaction coefficients for each origin-destination combination; and $\gamma \mathbf{X}$ is a vector of control variables (here: age, gender, education, migration background, country, and survey round). ${ }^{7}$ In our case, $\alpha_{o}$ and $\beta_{d}$ are informative of class voting patterns, while mobility effects are computed as contrasts $\Delta \delta$ of the coefficients $\delta_{o d}$ and $\delta_{o o}$ (i.e., $\delta_{o d}-\delta_{o o}$ ) in the above-described fashion. ${ }^{8}$

To our best knowledge, the present study is pioneer in applying MCM to the investigation of voting behaviour. Yet its advantages over competing methods are evident. As it emerges clearly from the above, the scholarly debate rises expectations on mobility effects that are class-specific. This means that, for instance, upward mobility is expected to be associated with left voting among the high-skilled service class only. Although hypotheses such as this one are theoretically plain, they have simply not been tested in extant research - not considering mere cross-tabulation analyses. Hence, scholars have devoted massive attention to single average upward or downward mobility effects, while neglecting the existence of class-specific ones - and avoiding questioning it.

The said limitation has methodological grounds too. For decades, mobility research has quasi exclusively relied on the Diagonal Reference Model (Sobel 1981, 1985), an odd method that, differently from OLS, promises to identify mobility effects while holding class and social origin constant. ${ }^{9}$. Doing so is crucial to avoid omitted variable bias. Unfortunately, DRM is unsuitable to test class-specific mobility effects. ${ }^{10}$ Using MCM allows us to do so and represents a clear progress with respect to extant research. Moreover, DRM has been rightly criticised for relying on unclear assumptions and being likely to bias mobility estimates downward (Fosse and Pfeffer 2021), which further questions the soundness of previous findings and calls for a change of course. Conversely, MCM enables us not

\footnotetext{
${ }^{6}$ We use the term "effect" for the sake of simplicity, and the usual disclaimer in non-causal research applies.

${ }^{7}$ As in any ANOVA model, $\alpha_{o}, \beta_{d}$ and $\delta_{o d}$ are deviations from the grand mean $\mu$.

${ }^{8}$ In the example above, the upward mobility effect resulting from ascending from the working class $(w)$ to the middle class $(m)$ is computed as the following contrast: $\delta_{w m}-\delta_{m m}$.

${ }^{9}$ OLS does not allow to identify the separate effect of the three variables mobility, origin and destination because these are linearly dependent (Blalock 1966, 1967; Hendrickx et al. 1993).

${ }^{10}$ In principle, DRM allows for some sort of heterogenous mobility effects. However, because it requires to specify origin and destination effects based on a purely hierarchical class division, it is unsuitable to control for horizontal differences in voting behaviour, and these are likely to be wrongly captured by the said heterogenous mobility effects.
} 
to depart from the well-known framework of OLS, with no specific model assumptions. ${ }^{11}$

\section{Variables and operationalisation}

Our main dependent variable is voting behaviour. Our operationalisation of centre-left and centreright parties follows the ParlGov classification. The former party family mainly includes socialdemocrats and green parties, while the latter includes liberal, conservative and christian-democrats. Our operationalization of radical left and radical right parties follows the PopuList classification. We provide a list of examined PRR parties in appendix. For the purpose of modelling radical left and right voting, we restrict our sample to those elections where a radical left or right party have been electorally relevant. ${ }^{12}$ ESS respondents' voting choices are operationalized by means of the dataset PartyFacts. We refer to the appendix for the operationalisation of other dependent variables.

Our main explanans is social mobility. Our operationalisation of social class is based on an adaptation of Oesch's (2006b; 2006c) class scheme. We chose it over competing class schemes as it accounts for the increasing heterogeneity within the middle class as well as the emergence of non-industrial lower-skilled occupations (Kitschelt 2012; Knutsen and Langsæther 2015). This feature is critical for testing our hypotheses, which are class-specific. This scheme has been extensively used in class voting literature (Beramendi et al. 2015; Rydgren 2012), but it much rarer in mobility research (Ares 2020; van Ditmars 2020). For the sake of parsimony, we simplify the original scheme and reduce the 17 classes down to 9 (see figure in appendix). ${ }^{13}$ We do not consider using a purely hierarchical scheme - or an index, such as ISEI - because horizontal class divisions are known to be critical for political behaviour. As it is the custom, we operationalise parental class following the domination approach; however, if the two parents rank equally, father's class prevails. We refer to the appendix for the operationalisation of the control variables.

\section{Results}

Because our scheme contains 9 social classes, MCM provides us with 28 class-specific coefficients for upward mobility, and the same for downward mobility. ${ }^{14}$ For purposes of readability, we refrain from listing all of them for each of our models. With the aim of testing our hypotheses, we take the

\footnotetext{
${ }^{11}$ This not only improves the legibility of our identification strategy, but also makes it possible to compare the magnitude of mobility effects with origin and destination ones (e.g., comparing the effect of being downwardly mobile in the working class and the fact of simply belonging to the working class), contrarily to DRM.

${ }^{12}$ For this purpose, we only select those elections where these parties have scored at least $5 \%$ in the weighted sample.

${ }^{13}$ We keep all the four original vertical levels, as this is critical to study mobility, we consider the petty bourgeoisie as a separate category, and we maintain the main horizontal divisions among employees, that is between socio-cultural professionals and the other professionals at the top, and between industrial jobs and those demanding some social skills at the bottom.

${ }^{14}$ The original interaction coefficients are $9^{2}=81$. Some of them concern horizontally mobility so we do not use them. 9 of them are interaction coefficients for the immobile individuals (one per each class), and they serve as reference for computing the 28 contrasts for the upwardly and downwardly mobile).
} 
weighted average of the appropriate coefficients in each case, and report the main results in table $1 .{ }^{15}$ We display and interpret individual class-specific coefficients in text on occasion.

On average, we do not find confirmation for the hypothesis that upward mobility increases voting for a left party (H1), as the coefficient is not statistically significant - and even goes in the opposite direction we would expect. Also, we do not find any relevant difference between ascending to the service upper and middle class (H1a), i.e., socio-cultural professionals and semi-professionals, or the managerial one (H1b), i.e., businessmen and associate managers. For these, the effect is similar to the main one.

At a closer inspection to the single class-specific coefficients, we observe that all of them are not significant, except for the coefficient for socio-cultural semi-professionals whose parents were skilled manual workers. This group represents $10 \%$ of the upwardly mobile population and is female-dominated. ${ }^{16}$ A prototypical example of this group would be primary school teachers whose father was a skilled blue-collar worker. The coefficient for this group is negative and equals to -0.08 (p-value $<0.01, \mathrm{SE}$ $=0.03)$. This means that the average electoral support for left parties among the offspring of skilled manual workers who experience upward mobility into the class of socio-cultural semi-professionals is 8 p.p. lower than among those who remain in the same class as their parents, holding origin and destination effects constant. The magnitude of this effect is substantial, given that the average support for left parties is $36 \%$ (while the grand mean is $41 \%$ ). By way of comparison, we can look at the destination main effects (table 2) that picture class voting patterns, net of social origin and mobility. The said result is comparable to the effect of belonging to the petty bourgeoisie $(-10$ p.p.), and is double the one of the managerial class ( -4 p.p. among both businessmen and associate managers).

Table 1: Voting choice, Mobility contrasts (average), MCM (LPM)

\begin{tabular}{lcccccc}
\hline & Right & Left & Center-right & Center-left & Rad. right & Rad. left \\
\hline Upward & 0.01 & -0.01 & -0.00 & -0.01 & 0.01 & $-0.02^{*}$ \\
& $(0.01)$ & $(0.01)$ & $(0.01)$ & $(0.01)$ & $(0.01)$ & $(0.01)$ \\
Downward & 0.01 & -0.00 & 0.01 & -0.01 & $-0.02^{*}$ & 0.01 \\
& $(0.01)$ & $(0.01)$ & $(0.01)$ & $(0.01)$ & $(0.01)$ & $(0.01)$ \\
Upward in service & 0.02 & -0.02 & 0.00 & -0.01 & 0.01 & -0.03 \\
& $(0.01)$ & $(0.01)$ & $(0.01)$ & $(0.01)$ & $(0.01)$ & $(0.02)$ \\
Upward in non-service & 0.01 & -0.01 & -0.00 & -0.01 & 0.01 & -0.02 \\
Downward in working class & $(0.01)$ & $(0.01)$ & $(0.01)$ & $(0.01)$ & $(0.01)$ & $(0.01)$ \\
& 0.01 & -0.01 & 0.02 & -0.01 & -0.01 & 0.00 \\
& $(0.01)$ & $(0.01)$ & $(0.01)$ & $(0.01)$ & $(0.01)$ & $(0.01)$ \\
\hline Obs & 162010 & 162010 & 162010 & 162010 & 65617 & 71001 \\
\hline
\end{tabular}

All models estimated with individual-level controls and country and year FE. Robust standard errors in parentheses. ${ }^{*} p<0.05,{ }^{* *} p<0.01,{ }^{* * *} p<0.001$.

\footnotetext{
${ }^{15}$ For instance, we sum up all the 28 contrasts for the downwardly mobile by weighting each for the sample size of the respective origin-destination combination. This provides us with a single coefficient for a downward mobility effect.

${ }^{16}$ This figure is not negligeable: the biggest group is $15 \%$ of the upwardly mobile population.
} 
Table 2: Voting choice, Destination effects, MCM (LPM)

\begin{tabular}{lcccccc}
\hline & Right & Left & Center-right & Center-left & Rad. right & Rad. left \\
\hline Businessmen & $0.06^{* * *}$ & $-0.04^{* * *}$ & $0.08^{* * *}$ & $-0.04^{* * *}$ & $-0.04^{* * *}$ & 0.00 \\
& $(0.01)$ & $(0.01)$ & $(0.01)$ & $(0.01)$ & $(0.01)$ & $(0.01)$ \\
Petty bourgeoisie & $0.10^{* * *}$ & $-0.10^{* * *}$ & $0.10^{* * *}$ & $-0.09^{* * *}$ & 0.00 & $-0.03^{* * *}$ \\
& $(0.01)$ & $(0.01)$ & $(0.01)$ & $(0.01)$ & $(0.01)$ & $(0.01)$ \\
Associate manag. & $0.04^{* * *}$ & $-0.04^{* * *}$ & $0.06^{* * *}$ & $-0.03^{*}$ & $-0.03^{* * *}$ & $-0.02^{* *}$ \\
& $(0.01)$ & $(0.01)$ & $(0.01)$ & $(0.01)$ & $(0.01)$ & $(0.01)$ \\
Skilled manual & 0.01 & $-0.03^{*}$ & $-0.03^{*}$ & $-0.03^{*}$ & $0.09^{* * *}$ & -0.01 \\
& $(0.01)$ & $(0.01)$ & $(0.01)$ & $(0.01)$ & $(0.02)$ & $(0.01)$ \\
Unskilled manual & $-0.06^{* * *}$ & $0.05^{* *}$ & $-0.09^{* * *}$ & $0.05^{* *}$ & $0.05^{*}$ & 0.00 \\
Socio-c. prof. & $(0.02)$ & $(0.02)$ & $(0.01)$ & $(0.02)$ & $(0.02)$ & $(0.01)$ \\
Socio-c. semi-prof. & $-0.05^{* *}$ & $0.03^{*}$ & -0.02 & 0.02 & $-0.06^{* * *}$ & $0.05^{*}$ \\
& $(0.02)$ & $(0.02)$ & $(0.02)$ & $(0.01)$ & $(0.01)$ & $(0.02)$ \\
Skilled service & $\left(0.06^{* * *}\right.$ & $0.09^{* * *}$ & $-0.04^{* *}$ & $0.08^{* * *}$ & $-0.06^{* * *}$ & $0.02^{*}$ \\
Unskilled service & 0.00 & $(0.01)$ & $(0.01)$ & $(0.01)$ & $(0.01)$ & $(0.01)$ \\
& $(0.01)$ & $(0.01)$ & $(0.01)$ & $(0.01)$ & $(0.01)$ & $(0.01)$ \\
\hline Obs & $-0.04^{* *}$ & $0.04^{* *}$ & $-0.06^{* * *}$ & $0.04^{* *}$ & $0.05^{* *}$ & -0.00 \\
\hline
\end{tabular}

All models estimated with individual-level controls and country and year FE. Robust standard errors in parentheses. ${ }^{*} p<0.05,{ }^{* *} p<0.01,{ }^{* * *} p<0.001$.

Finally, it is robust to the inclusion of non-voters and to restricting the analysis to the survey rounds (1-5) for which detailed information on parental class is available.

Subsequently, we model voting behaviour for the centre-left (i.e., social-democrats and green) and the radical left separately. In this case, some heterogeneity in the average effect emerges. Centreleft parties clearly drive the null effect on left voting we discussed above: upward mobility has no significant impact on voting for centre-left parties, but there is a negative association with voting for far-left ones. The latter score 3 p.p. lower among voters on an ascending trajectory. ${ }^{17}$ This effect is mostly driven by the above-mentioned group of socio-cultural semi-professionals whose parents were skilled manual workers $(\Delta \delta=-0.04, \mathrm{p}$-value $<0.05, \mathrm{SE}=0.02) .{ }^{18}$ Although it was not visible in the overall effect, centre-left parties too are less successful among this group $(\Delta \delta=-0.07, \mathrm{p}<0,01$, $\mathrm{SE}=0.02) \cdot{ }^{19}$ In both cases, the effect magnitude is considerable, especially with respect to radical left voting, as the average score for this party family is $8 \%$ (grand mean $=9$ ) - while it is $36 \%$ for centre-left parties (grand mean $=38$ ). By way of comparison, the score of centre-left among the petty bourgeoisie is 9 p.p. lower than on average, and the one of the far-left parties is 3 p.p. lower. Both

\footnotetext{
${ }^{17}$ This result is robust to the inclusion of non-voters, but not to restricting the analysis to the non-imputed sample.

${ }^{18}$ All other class-specific coefficients are non-significant except for socio-cultural semi-professionals whose parents were unskilled service workers $(\Delta \delta=-0.06, \mathrm{p}$-value $<0.05, \mathrm{SE}=0.03)$. However, because the sample size of this group is very modest, and the result is robust to the inclusion of non-voters but not to restricting the analysis to the first five survey rounds, we gloss over it for the sake of brevity.

${ }^{19}$ Their effect is robust to the inclusion of non-voters and restricting the sample to the first five survey rounds. All other class-specific coefficients are non-significant.
} 
these figures are very close to the ones we observe for the above class-specific upward mobility effect.

We then turn to (centre-)right parties. We do not find any statistically significant association between overall upward mobility and voting for right parties, neither moderate nor radical (H2). Additionally, results do not provide confirmation for Goldthorpe's (1982) expectation: moving up to the highest levels of the social ladder, especially in the managerial sector, does not increase conservative voting. Nonetheless, we do find class-specific mobility effects in this case too. The most noteworthy group is the offspring of associate managers who succeeded in attaining the very last stage in the social ladder and became businessmen. ${ }^{20}$ Centre-right parties score 4 p.p. higher (p-value $<0.05, \mathrm{SE}$ $=0.02$ ) in this group than among the offspring of associate managers who did not break away from their parents' class. ${ }^{21}$ This effect is not negligeable, though smaller than what we observed above for left voting: the average score of centre-right parties in the sample is $39 \%$ (grand mean $=36$ ). By way of comparison, the support of petty bourgeois is 10 p.p. higher (than the average), businessmen's one is 8 p.p., associate managers' one is 6 p.p.. Finally, this effect is robust to the inclusion of non-voters and to restricting the analysis to the five survey rounds for which detailed information on parental class is available.

To further corroborate the findings presented above, we investigate whether upwardly mobile individuals have distinct economic and cultural attitudes (table 3). We do not find any statistically significant effect of social ascent on either economic reformism (conservatism) or cultural openness (traditionalism) - which are two predictors of left (right) voting, thus confirming our observations on voting choice. ${ }^{22}$ The two groups we discussed earlier are no exception in the respect. Nonetheless, we do observe some interesting evidence with respect to socio-cultural semi-professionals whose parents were skilled manual workers - among which left voting is less common. These tend to be more rightleaning $(\Delta \delta=0.25, \mathrm{p}$-value $<0.01, \mathrm{SE}=0.09)$ and trust politicians to a lesser extent $(\Delta \delta=-0.25$,

\footnotetext{
${ }^{20}$ All other class-specific coefficients are non-significant, except for socio-cultural professionals whose parents were unskilled manual workers. However, because the sample size of this group is very modest, and the result is not robust either to the inclusion of non-voters or restricting the analysis to the first five rounds, we gloss over it for the sake of brevity.

${ }^{21}$ We focus our interpretation on centre-right parties both for theoretical reasons and because the effect on radical right voting is not significant.

${ }^{22}$ We do find a significant association with favourable redistribution attitudes only, which would go in the direction of our original hypothesis (H1) and question the results above. However, the effect magnitude (-0.04) is negligeable and thus we deem this result implausible: it is one twenty-fifth of the standard deviation, and one fourth of the effect of being unskilled manual worker $(-0.19)$. Regarding the economic dimension, all class-specific effects are not different from zero, except for the one of associate managers from the skilled manual working class $(\Delta \delta=-0.08$, p-value $<$ $0.05, \mathrm{SE}=0.04)$, who appear to be more (economically) left-leaning. The effect magnitude is non-negligeable: it is one sixth of the standard deviation, and it is comparable to the effect of being a socio-cultural semi-professional (which also equals to -0.09$)$ and even exceeds the effect of being socio-cultural professional $(-0.06)$ or unskilled manual worker $(-0.05)$. Nonetheless, the size of this group is quite modest (around $2 \%$ ), the result is not robust to sample restriction, and it is not consistent with the above null findings on voting choice. Regarding the cultural dimension, we find five class-specific significant effects. Only two of them are robust to sample restriction: socio-cultural professionals from the petty bourgeoisie and unskilled manual workers from the petty bourgeoisie are both more culturally conservative. The former is substantial $(\Delta \delta=0.31, \mathrm{p}$-value $<0.05, \mathrm{SE}=0.12)$ - and it outperforms all (own) class effects - but it concerns a negligeable group in size terms (less than $1 \%$ of the upwardly mobile). Besides, it is not consistent with the above null findings on voting choice.
} 
Table 3: Attitudes, Mobility contrasts (average), MCM (LPM)

\begin{tabular}{lcccc}
\hline & Left-right & Eco. dim. & Cult. dim. & Polit. trust \\
\hline Upward & 0.02 & -0.01 & -0.01 & -0.06 \\
Downward & $(0.04)$ & $(0.01)$ & $(0.01)$ & $(0.04)$ \\
& 0.00 & -0.00 & -0.01 & -0.00 \\
Upward in service & $(0.03)$ & $(0.01)$ & $(0.01)$ & $(0.03)$ \\
Upward in non-service & 0.06 & -0.01 & -0.01 & -0.09 \\
Downward in working class & $(0.06)$ & $(0.01)$ & $(0.02)$ & $(0.06)$ \\
& 0.02 & -0.01 & -0.02 & -0.01 \\
& $(0.04)$ & $(0.01)$ & $(0.01)$ & $(0.04)$ \\
Obs & 0.01 & 0.00 & -0.01 & -0.05 \\
& $(0.05)$ & $(0.01)$ & $(0.02)$ & $(0.05)$ \\
\hline
\end{tabular}

All models estimated with individual-level controls and country and year FE. Robust standard errors in parentheses. ${ }^{*} p<0.05,{ }^{* *} p<0.01,{ }^{* * *} p<0.001$.

p-value $<0.05, \mathrm{SE}=0.10) .{ }^{23}$ These results may explain why, overall, this group tends to vote less for left parties, without featuring an overrepresentation of right-voters or abstainers. In both cases, the effect size is not impressive per se (slightly less than one tenth of the standard deviation) but their order of magnitude is similar to the (own) class effects.

Afterwards, we turn to the electoral preferences of downwardly mobile voters. On average, these do not feature a higher proportion of supporters for radical parties (H3), neither on the left (H3a) nor on the right (H3b). We also do not find support for the hypothesis that radical right voting would be more widespread among downwardly mobile lower-class workers (H3c). Furthermore, the only significant class-specific effect we observe goes in the opposite direction we would expect: skilled manual workers whose parents were associate managers tend to vote less for radical parties - a group that makes up $13 \%$ of the downwardly mobile sample. This effect is driven by far-right parties, who score 7 p.p. less (p-value $<0.01, \mathrm{SE}=0.02$ ) among this group. ${ }^{24}$ It is robust to the inclusion of non-voters, though not to restricting the analysis to the first five rounds. We also find two additional significant (and similarly negative) effects on radical right voting on two other groups: offspring of socio-cultural professionals who have become either petty bourgeois or unskilled service workers. Both are robust to restricting the sample to the first five rounds and the inclusion of non-voters. Nonetheless, because the sample size of these two groups is very modest, we gloss over them for the sake of brevity.

The magnitude of the observed effect on the said subgroup of associate managers is noteworthy, considering that $9 \%$ of our sample (grand mean $=10$ ) supports this party family. It is even comparable than the effect of being socio-cultural (semi-)professional, which equals to -6 p.p.. This is remarkable,

\footnotetext{
${ }^{23}$ Both results are robust to restricting the sample to the first five rounds.

${ }^{24}$ We also find some significant class-specific (positive) effects on radical left voting, though none of them is robust to the analysis on the restricted sample. Additionally, results on attitudes (for these groups) are not entirely consistent and none of them is robust to the restricted sample.
} 
as the said constituency is known to be particularly inimical to the far right. Data on political attitudes partly confirm these results. Skilled manual workers whose parents were associate managers have further political trust $(\Delta \delta=0.20$, p-value $<0.05, \mathrm{SE}=0.08) .{ }^{25}$ They may also be more left-leaning $(\Delta \delta=-0.16, \mathrm{p}$-value $<0.05, \mathrm{SE}=0.08)$ and vote more for left parties, $(\Delta \delta=0.04, \mathrm{p}$-value $<0.05$, $\mathrm{SE}=0.02)$, namely centre-left ones $(\Delta \delta=0.04, \mathrm{p}$-value $<0.05, \mathrm{SE}=0.02)$, though none of these latter effects is robust to restricting the sample to the first five rounds.

\section{Discussion and conclusions}

Scholarly literature posits that the gradual changes in the occupational structure have transformed traditional patterns in class voting. On the one hand, left parties have survived to deindustrialization by co-opting an impressive portion of socially ascending voters. On the other, the recent increase in downward mobility has created an electoral reservoir for radical parties. Nonetheless, extant literature provides inconclusive evidence for the alleged consequences of social mobility as well as their reasons. We consider this limitation to stem from a considerable discrepancy between theory and empirical methods. To overcome this issue, the present study applies the Mobility Contrast Model, a cutting-edge approach allowing to identify class-specific mobility effects on voting (rather than mere average ones), while holding other relevant factors constant and without departing from the well-known framework of OLS.

Our research provides little to not support for extant scholarly accounts on the relation between social ascent and the left or social descent and radical politics, though without concluding that mobility is inconsequential for voting choice. Contrarily, we do find some substantial (and significant) class-specific mobility effects. Firstly, we do not find evidence for the argument that left parties disproportionately benefit from occupational upgrading because of mobility. If anything, these parties are less successful among the social group of socio-cultural semi-professionals whose parents were skilled manual workers. This relation is driven by a combination of centrism and political distrust. Interestingly, it has the same order of magnitude as being a petty bourgeois. A possible explanation - which we do not test - for this observation could be that experiencing an increase in own social status, in this case, does not correspond to an equivalent increase in living standards, given the modest economic advantage the upper-middle service class enjoys, namely relatively to the highest strata of the industrial working class (Emmenegger et al. 2012; Häusermann et al. 2015).

We also find some evidence that social ascent favours centre-right voting among the offspring of associate managers that became businessmen - though not among the remaining population on average. A possible reason of the exceptionalism of this subgroup is that its members may interpret

\footnotetext{
${ }^{25}$ This result is robust to restricting the sample to the first five rounds.
} 
their ascending trajectory in a very idiosyncratic way: they may consider that individual effort is crucial for life success precisely because they originate from a managerial class that itself is known to see inequalities as a natural phenomenon. Once again, social origin and mobility effects appear to be intrinsically intertwined, which further justifies our flexible approach. However, testing the said mechanism would require further survey data - notably on voters' beliefs about inequality - that we do not consider in the present study for the sake of parsimony.

Similarly, claims that downward mobility is associated with political discontent and radical voting do not find confirmation in our analyses. If anything, we observe that radical right parties score less among some branches of the socially descending population. This is notably the case of skilled manual workers whose parents were associate managers. Political trust also appears to be more widespread among this group. Unfortunately, speculating the reasons of this specificity goes beyond the scope of the present analysis.

To conclude, the present study contributes to the debate on the socio-economic determinants of electoral behaviour by showing that current patterns in class voting result from a complex combination of three factors: voters' own class, their social origin, and their possible experience of mobility. While previous studies have empirically focused on average effects, ours adopts a peculiar approach to highlight that, although such effects may be indistinguishable from zero, mobility does influence voting choice in a substantial manner, though solely among certain social groups. The most notable findings concern occupational upgrading. On the one hand, it increases the size of the high-skilled service class, a group that is known to be close to left parties. On the other, social ascent depresses left voting among a non-negligeable proportion of high-skilled service and non-service class voters. To some extent, the two effects tend to cancel out each other - at least partly. Because long-term economic transformations are likely to further shape European politics, it is vital to distinguish the mechanisms through which this occurs to predict future electoral developments. 


\section{References}

Abramson, P. R. And J. W. Books (1971): "Social Mobility and Political Attitudes: A Study of Intergenerational Mobility among Young British Men," Comparative Politics, 3, 403.

Albert, A. And J. A. Anderson (1984): "On the existence of maximum likelihood estimates in logistic regression models," Biometrika, 71, 1-10.

Alesina, A. And E. La Ferrara (2005): "Preferences for redistribution in the land of opportunities," Journal of Public Economics, 89, 897-931.

Alesina, A., S. Stantcheva, and E. Teso (2018): "Intergenerational Mobility and Preferences for Redistribution," American Economic Review, 108, 521-554.

Ares, M. (2020): "Changing classes, changing preferences: how social class mobility affects economic preferences," West European Politics, 43, 1211-1237, publisher: Routledge _eprint: https://doi.org/10.1080/01402382.2019.1644575.

Autor, D. H. AND D. Dorn (2013): "The Growth of Low-Skill Service Jobs and the Polarization of the US Labor Market," American Economic Review, 103, 1553-1597.

Baccini, L. ANd T. Sattler (2021): "Austerity, Economic Vulnerability, and Populism," SSRN Scholarly Paper ID 3766022, Social Science Research Network, Rochester, NY.

Benabou, R. And E. A. Ok (2001): "Social Mobility and the Demand for Redistribution: The Poum Hypothesis," The Quarterly Journal of Economics, 116, 447-487, publisher: Oxford Academic.

Beramendi, P., S. Häusermann, H. Kitschelt, and H. Kriesi, eds. (2015): The Politics of Advanced Capitalism, Cambridge: Cambridge University Press.

Berman, E., J. Bound, And S. Machin (1998): "Implications of Skill-Biased Technological Change: International Evidence*," The Quarterly Journal of Economics, 113, 1245-1279.

Blalock, H. M. (1966): "The Identification Problem and Theory Building: The Case of Status Inconsistency," American Sociological Review, 31, 52-61, publisher: [American Sociological Association, Sage Publications, Inc.].

(1967): "Status Inconsistency, Social Mobility, Status Integration and Structural Effects," American Sociological Review, 32, 790-801, publisher: [American Sociological Association, Sage Publications, Inc.].

Bonikowski, B. (2017): "Ethno-nationalist populism and the mobilization of collective resentment," The British Journal of Sociology, 68, S181-S213, _eprint: https://onlinelibrary.wiley.com/doi/pdf/10.1111/1468-4446.12325.

BreEn, R. (2001): "Social mobility and constitutional and political preferences in Northern Ireland," The British Journal of Sociology, 52, 621-645, _eprint: https://onlinelibrary.wiley.com/doi/pdf/10.1080/00071310120084508.

Breen, R., ed. (2004): Social mobility in Europe, Oxford ; New York: Oxford University Press, oCLC: ocm56539319.

BreEN, R. AND W. MÜLLER, eds. (2020): Education and intergenerational social mobility in Europe and the United States, Studies in social inequality, Stanford, California: Stanford University Press.

Bukodi, E. And J. H. Goldthorpe (2018): Social Mobility and Education in Britain: Research, Politics and Policy, Cambridge: Cambridge University Press.

Bukodi, E. AND M. PASKov (2020): "Intergenerational Class Mobility among Men and Women in Europe: Gender Differences or Gender Similarities?" European Sociological Review, 36, 495-512.

Bukodi, E., M. Paskov, and B. Nolan (2020): "Intergenerational Class Mobility in Europe: A New Account," Social Forces, 98, 941-972, publisher: Oxford Academic. 
Burgoon, B., S. van Noort, M. Rooduijn, and G. Underhill (2019): "Positional deprivation and support for radical right and radical left parties," Economic Policy, 34, 49-93.

Checchi, D. (2006): The Economics of Education: Human Capital, Family Background and Inequality, Cambridge University Press, google-Books-ID: 2zfF4wHltvYC.

Cohen, J. (1987): "Parents as Educational Models and Definers," Journal of Marriage and Family, 49, 339-351, publisher: [Wiley, National Council on Family Relations].

Colantone, I. And P. Stanig (2018a): "Global Competition and Brexit," American Political Science Review, 112, 201-218, publisher: Cambridge University Press.

(2018b): "The Trade Origins of Economic Nationalism: Import Competition and Voting Behavior in Western Europe," American Journal of Political Science, 62, 936-953.

Corneo, G. And H. P. Grüner (2002): "Individual preferences for political redistribution," Journal of Public Economics, 83, 83-107.

Crafts, N. And T. Giovanni (1996): Economic Growth in Europe Since 1945, Cambridge University Press, google-Books-ID: wiTtnUn5qGsC.

Daenekindt, S., J. VAn Der WaAl, And W. De Koster (2018): "Social mobility and political distrust: cults of gratitude and resentment?" Acta Politica, 53, 269-282.

Dustmann, C. (2004): "Parental background, secondary school track choice, and wages," Oxford Economic Papers, 56, 209-230.

DöRING, H. AND P. MANOW (2019): "Parliaments and governments database (ParlGov): Information on parties, elections and cabinets in modern democracies. Development version." .

DöRing, H. And S. Regel (2019): "Party Facts: A database of political parties worldwide," Party Politics, 25, 97-109, publisher: SAGE Publications Ltd.

Emmenegger, P., S. Häusermann, B. Palier, And M. Seeleib-Kaiser, eds. (2012): The Age of Dualization: The Changing Face of Inequality in Deindustrializing Societies, Oxford University Press.

Erikson, R. And J. H. Goldthorpe (1992): The constant flux: A study of class mobility in industrial societies, Oxford University Press.

European Social Survey ERIC (ESS ERIC) (2019): "European Social Survey (ESS), Round 9 - 2018," Publisher: NSD - Norwegian Centre for Research Data.

Fetzer, T. (2019): "Did Austerity Cause Brexit?" American Economic Review, 109, 3849-3886.

Fosse, E. And F. T. Pfeffer (2021): "Beyond the Diagonal Reference Model: Critiques and New Directions," .

Ganzeboom, H. B. G. (2013): "ISCO-88 Codes for Parental Occupations in the European Social Survey, Rounds 1-2-3-4-5," .

Gest, J., T. Reny, And J. Mayer (2018): "Roots of the Radical Right: Nostalgic Deprivation in the United States and Britain," Comparative Political Studies, 51, 1694-1719.

Gidron, N. And P. A. Hall (2017): "The politics of social status: economic and cultural roots of the populist right," British Journal of Sociology, 28.

Gidron, N. And J. J. B. MiJs (2019): "Do Changes in Material Circumstances Drive Support for Populist Radical Parties? Panel Data Evidence from the Netherlands during the Great Recession, 2007-2015," European Sociological Review, 0, 14.

Gingrich, J. AND S. HÄUSERMAnN (2015): "The decline of the working-class vote, the reconfiguration of the welfare support coalition and consequences for the welfare state," Journal of European Social Policy, 25, 50-75. 
Goldthorpe, J. (1982): "On the service class, its formation and future," in Social class and the division of labour: Essays in honour of Ilya Neustadt, 162, publisher: CUP Archive.

Green, J., T. Hellwig, And E. Fieldhouse (2021): "Who Gets What: The Economy, Relative Gains and Brexit," British Journal of Political Science, 1-19.

Green, J. And R. Shorrocks (2021): "The Gender Backlash in the Vote for Brexit," Political Behavior.

HeAth, A. F., ed. (1991): Understanding political change: the British voter, 1964-1987, Oxford, England ; New York: Pergamon Press, 1st ed ed.

Hendrickx, J., N. D. De Graaf, J. Lammers, And W. Ultee (1993): "Models for status inconsistency and mobility: A comparison of the approaches by Hope and Sobel with the mainstream square additive model," Quality and Quantity, 27, 335-352.

Hill, M. S. And G. J. Duncan (1987): "Parental family income and the socioeconomic attainment of children," Social Science Research, 16, 39-73.

Hyman, H. H. (1942): "The psychology of status," Archives of Psychology (Columbia University), 269, 94-94.

HÄusermann, S., T. Kurer, And H. Schwander (2015): "High-skilled outsiders? Labor market vulnerability, education and welfare state preferences," Socio-Economic Review, 13, 235-258.

Im, Z. J., N. Mayer, B. Palier, And J. Rovny (2019): "The "losers of automation": A reservoir of votes for the radical right?" Research \& Politics, 6, 205316801882239.

Inglehart, R. (1977): The Silent Revolution: Changing Values and Political Styles Among Western Publics, Princeton University Press, google-Books-ID: wX59BgAAQBAJ.

JaCKSOn, M. AND D. B. GRusky (2018): "A post-liberal theory of stratification," The British Journal of Sociology, 69, 1096-1133, _eprint: https://onlinelibrary.wiley.com/doi/pdf/10.1111/14684446.12505 .

Jaime-Castillo, A. M. And I. Marqués-Perales (2019): "Social mobility and demand for redistribution in Europe: a comparative analysis," The British Journal of Sociology, 70, 138-165, _eprint: https://onlinelibrary.wiley.com/doi/pdf/10.1111/1468-4446.12363.

Johnson, M. K. (2002): "Social Origins, Adolescent Experiences, and Work Value Trajectories during the Transition to Adulthood*," Social Forces, 80, 1307-1340.

Kitschelt, H. (1994): The transformation of European social democracy, Cambridge University Press.

(2012): "Social class and the radical right: Conceptualizing political preference formation and partisan choice," in Class politics and the radical right, ed. by J. Rydgren, Routledge, 242-269.

Kitschelt, H. And P. Rehm (2014): "Occupations as a Site of Political Preference Formation," Comparative Political Studies, 47, 1670-1706.

Knutsen, O. and P. Langsæther (2015): "Class Voting in Western Europe: Do Various Class Schemas Make a Difference?" .

KRIESI, H. (1998): "The transformation of cleavage politics: The 1997 Stein Rokkan lecture," European Journal of Political Research, 33, 165-185, _eprint: https://ejpr.onlinelibrary.wiley.com/doi/pdf/10.1111/1475-6765.00379.

Kurer, T. (2020): "The Declining Middle: Occupational Change, Social Status, and the Populist Right," Comparative Political Studies, 0010414020912283, publisher: SAGE Publications Inc.

Kurer, T. And B. PAlier (2019): "Shrinking and shouting: the political revolt of the declining middle in times of employment polarization," Research \& Politics, 6, 205316801983116. 
Kurer, T. And B. van StaAlduinen (2020): "Disappointed Expectations: Downward Mobility and Electoral Change," .

Lipset, S. M. (1959): "Some Social Requisites of Democracy: Economic Development and Political Legitimacy1," American Political Science Review, 53, 69-105, publisher: Cambridge University Press.

Luo, L. (2021): "Heterogenous Effects of Intergenerational Social Mobility: An Improved Method and New Evidence," Tech. rep., SocArXiv, type: article.

Margalit, Y. (2019): "Political Responses to Economic Shocks," Annual Review of Political Science, 22, 277-295,_eprint: https://doi.org/10.1146/annurev-polisci-050517-110713.

Marglin, S. AND J. Schor (1992): The golden age of capitalism: Reinventing the post-war experience, Oxford, UK: Clarendon Press.

Mayer, N. (2002): Ces français qui votent Le Pen, Paris: Flammarion.

Mayer, N. And P. Perrineau (1992): "Why do they vote for Le Pen?" European Journal of Political Research, 22, 123-141.

McAdams, J. (1987): "Testing the Theory of the New Class," The Sociological Quarterly, 28, 23-49, _eprint: https://onlinelibrary.wiley.com/doi/pdf/10.1111/j.1533-8525.1987.tb00281.x.

McCall, L. And J. Manza (2011): Class Differences in Social and Political Attitudes in the United States, Oxford University Press.

Mitrea, E. C., M. Mühlböck, And J. Warmuth (2020): "Extreme Pessimists? Expected Socioeconomic Downward Mobility and the Political Attitudes of Young Adults," Political Behavior.

Müller, W. (1999): "Class cleavages in party preferences in Germany-Old and new," in The End of Class Politics?: Class Voting in Comparative Context, ed. by G. Evans, New York: Oxford University Press, 137-180.

Oesch, D. (2006a): "Class Theorists and the Debate about the End of Class," in Redrawing the Class Map: Stratification and Institutions in Britain, Germany, Sweden and Switzerland, ed. by D. Oesch, London: Palgrave Macmillan UK, 11-26.

(2006b): "Coming to Grips with a Changing Class Structure: An Analysis of Employment Stratification in Britain, Germany, Sweden and Switzerland," International Sociology, 21, 263-288.

(2006c): Redrawing the Class Map: Stratification and Institutions in Britain, Germany, Sweden and Switzerland, London: Palgrave Macmillan UK.

Oesch, D. And G. Piccitto (2019): "The Polarization Myth: Occupational Upgrading in Germany, Spain, Sweden, and the UK, 1992-2015," Work and Occupations, 46, 441-469, publisher: SAGE Publications Inc.

Oesch, D. And L. Rennwald (2018): "Electoral competition in Europe's new tripolar political space: Class voting for the left, centre-right and radical right," European Journal of Political Research, 57, 783-807.

Paskov, M., P. PräG, AND L. Richards (2020): "Does downward social mobility make people more hostile towards immigrants?" Research in Social Stratification and Mobility, 100543.

Peugny, C. (2006): "La mobilité sociale descendante et ses conséquences politiques : recomposition de l'univers de valeurs et préférence partisane," Revue française de sociologie, 47, 443.

PIketty, T. (1995): "Social Mobility and Redistributive Politics," The Quarterly Journal of Economics, 110, 551-584, publisher: Oxford University Press.

Rooduijn, M., S. van Kessel, C. Froio, A. L. P. Pirro, D. L. Sarah L., D. Halikiopoulou, P. Lewis, C. Mudde, And P. Taggart (2019): "The PopuList: An Overview of Populist, Far Right, Far Left and Eurosceptic Parties in Europe," . 
Rydgren, J. (2012): Class Politics and the Radical Right, Routledge.

Schmoller, G. V. (1897): Was Verstehen Wir unter dem Mittelstande? Hat er im 19. Jahrhundert zu oder abgenommen?, Göttingen: Vandenhoeck und Ruprecht.

Siedler, T. And B. Sonnenberg (2012): "Intergenerational Earnings Mobility and Preferences for Redistribution," SSRN Electronic Journal.

Sobel, M. E. (1981): "Diagonal Mobility Models: A Substantively Motivated Class of Designs for the Analysis of Mobility Effects," American Sociological Review, 46, 893.

(1985): "Social Mobility and Fertility Revisited: Some New Models for the Analysis of the Mobility Effects Hypothesis," American Sociological Review, 50, 699.

Steenvoorden, E. And E. HARTEveld (2018): "The appeal of nostalgia: the influence of societal pessimism on support for populist radical right parties," West European Politics, 41, 28-52, publisher: Routledge _eprint: https://doi.org/10.1080/01402382.2017.1334138.

Tolsma, J., N. D. D. GraAf, And L. Quillian (2009): "Does intergenerational social mobility affect antagonistic attitudes towards ethnic minorities?" The British Journal of Sociology, 60, 257277, _eprint: https://onlinelibrary.wiley.com/doi/pdf/10.1111/j.1468-4446.2009.01230.x.

VAn Ditmars, M. M. (2020): "Opposing Forces? Intergenerational Social Mobility and the Transmission of Political Ideology," Swiss Journal of Sociology, 46, 369-395, publisher: Sciendo Section: Swiss Journal of Sociology. 


\section{Appendices}

\section{A List of parties}

[List of parties should go here]

\section{B Variables operationalisation}

\section{B.1 Class scheme}

Figure B.1: Oesch's class scheme and our adaptation

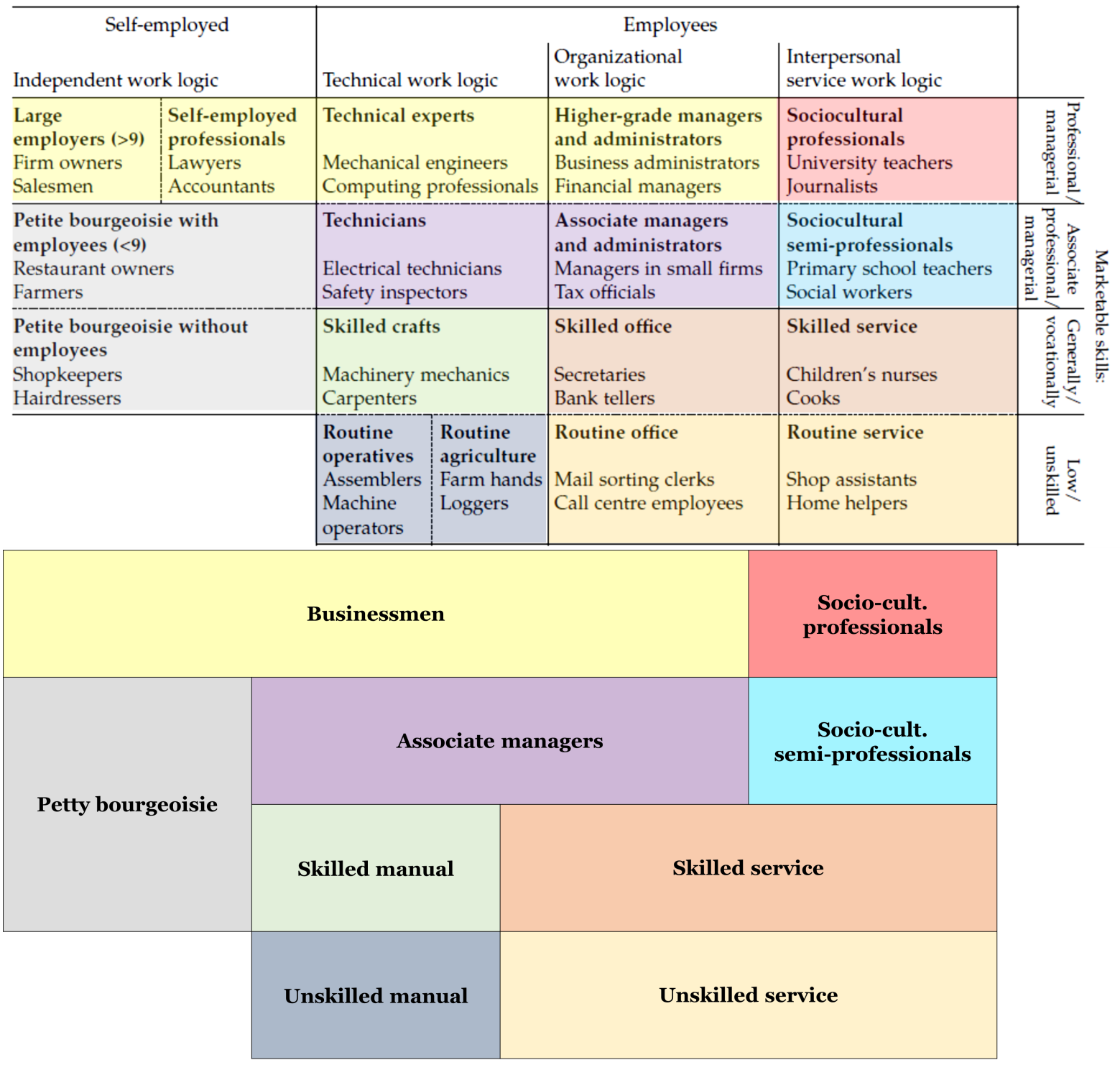

Notes: Oesch original scheme overlapped with our colours (above), our simplified version (below).

\section{B.2 Other dependent variables}

We construct two indexes of one's location on the economic and cultural dimension. The former is based on left-right placement, attitudes towards redistribution, and importance of equity in life. The latter is based on left-right placement (as earlier), attitudes towards migration (itself an index 
based on PCA), the EU and homosexuals. The two indexes are constructed using factor analysis with varimax rotation.

\section{Additional results}

Table C.1: Voting choice, Origin effects, MCM (LPM)

\begin{tabular}{lcccccc}
\hline & Right & Left & Center-right & Center-left & Rad. right & Rad. left \\
\hline Businessmen & $0.03^{* * *}$ & -0.01 & $0.04^{* * *}$ & -0.01 & $-0.02^{* * *}$ & -0.00 \\
Petty bourgeoisie & $(0.01)$ & $(0.01)$ & $(0.01)$ & $(0.01)$ & $(0.01)$ & $(0.01)$ \\
& 0.01 & -0.01 & -0.01 & -0.01 & 0.03 & -0.01 \\
Associate manag. & $0.02)$ & $(0.02)$ & $(0.02)$ & $(0.02)$ & $(0.02)$ & $(0.01)$ \\
& $(0.01)$ & -0.01 & 0.01 & -0.00 & -0.00 & -0.01 \\
Skilled manual & -0.00 & -0.00 & 0.00 & -0.00 & -0.01 & $(0.01)$ \\
Unskilled manual & $(0.01)$ & $(0.01)$ & $(0.01)$ & $(0.01)$ & $(0.01)$ & -0.01 \\
& $-0.03^{*}$ & $0.03^{* *}$ & $-0.03^{*}$ & 0.02 & 0.02 & $0.01)$ \\
Socio-c. prof. & $(0.01)$ & $(0.01)$ & $(0.01)$ & $(0.01)$ & $(0.01)$ & $(0.01)$ \\
Socio-c. semi-prof. & -0.01 & 0.01 & 0.00 & 0.01 & -0.02 & 0.01 \\
Skilled service & $0.01)$ & $(0.01)$ & $(0.01)$ & $(0.01)$ & $(0.01)$ & $(0.01)$ \\
& $(0.01)$ & $(0.01)$ & $(0.01)$ & $(0.01)$ & $(0.01)$ & -0.01 \\
Unskilled service & 0.01 & -0.00 & 0.01 & -0.00 & 0.00 & $(0.01)$ \\
& $(0.01)$ & $(0.01)$ & $(0.01)$ & $(0.01)$ & $(0.01)$ & -0.01 \\
\hline Obs & -0.04 & 0.00 & $-0.04^{*}$ & 0.01 & -0.00 & $(0.01)$ \\
\hline All & $(0.02)$ & $(0.02)$ & $(0.02)$ & $(0.02)$ & $(0.02)$ & $(0.02)$ \\
\hline
\end{tabular}

All models estimated with individual-level controls and country and year FE. Robust standard errors in parentheses. ${ }^{*} p<0.05,{ }^{* *} p<0.01,{ }^{* * *} p<0.001$. 
Table C.2: Attitudes, Destination effects, MCM (LPM)

\begin{tabular}{lcccc}
\hline & Left-right & Eco. dim. & Cult. dim. & Polit. trust \\
\hline Businessmen & $0.19^{* * *}$ & $0.10^{* * *}$ & $-0.10^{* * *}$ & $0.18^{* * *}$ \\
& $(0.04)$ & $(0.01)$ & $(0.01)$ & $(0.04)$ \\
Petty bourgeoisie & $0.43^{* * *}$ & $0.10^{* * *}$ & $0.03^{*}$ & -0.06 \\
& $(0.04)$ & $(0.01)$ & $(0.01)$ & $(0.04)$ \\
Associate manag. & $0.17^{* * *}$ & $0.06^{* * *}$ & -0.02 & $0.14^{* *}$ \\
& $(0.04)$ & $(0.01)$ & $(0.01)$ & $(0.04)$ \\
Skilled manual & 0.06 & $-0.03^{*}$ & $0.15^{* * *}$ & $-0.39^{* * *}$ \\
& $(0.05)$ & $(0.01)$ & $(0.01)$ & $(0.05)$ \\
Unskilled manual & $-0.09^{*}$ & $-0.05^{* * *}$ & $0.20^{* * *}$ & $-0.35^{* * *}$ \\
& $(0.05)$ & $(0.01)$ & $(0.02)$ & $(0.07)$ \\
Socio-c. prof. & $-0.36^{* * *}$ & $-0.06^{* * *}$ & $-0.21^{* * *}$ & $(0.08)$ \\
Socio-c. semi-prof. & $(0.07)$ & $(0.02)$ & $(0.02)$ & $0.25^{* * *}$ \\
& $-0.39^{* * *}$ & $-0.09^{* * *}$ & $-0.16^{* * *}$ & $(0.05)$ \\
Skilled service & $(0.05)$ & $(0.01)$ & $(0.02)$ & -0.05 \\
Unskilled service & $0.07^{*}$ & 0.00 & $0.03^{* *}$ & $(0.04)$ \\
& $(0.03)$ & $(0.01)$ & $(0.01)$ & $-0.18^{* * *}$ \\
\hline Obs & -0.08 & $-0.05^{* * *}$ & $0.09^{* * *}$ & $(0.05)$ \\
\hline All & $(0.05)$ & $(0.01)$ & $(0.01)$ & 192207 \\
\hline
\end{tabular}

All models estimated with individual-level controls and country and year FE. Robust standard errors in parentheses. ${ }^{*} p<0.05,{ }^{* *} p<0.01,{ }^{* * *} p<0.001$.

Table C.3: Attitudes, Origin effects, MCM (LPM)

\begin{tabular}{lcccc}
\hline & Left-right & Eco. dim. & Cult. dim. & Polit. trust \\
\hline Businessmen & 0.05 & $0.03^{* * *}$ & $-0.07^{* * *}$ & $0.11^{* * *}$ \\
& $(0.03)$ & $(0.01)$ & $(0.01)$ & $(0.03)$ \\
Petty bourgeoisie & 0.14 & $0.04^{*}$ & -0.01 & -0.06 \\
& $(0.08)$ & $(0.02)$ & $(0.02)$ & $(0.08)$ \\
Associate manag. & 0.01 & 0.01 & 0.00 & 0.02 \\
Skilled manual & $(0.02)$ & $(0.01)$ & $(0.01)$ & $(0.02)$ \\
& 0.02 & -0.00 & $0.04^{* * *}$ & -0.02 \\
Unskilled manual & $(0.02)$ & $(0.01)$ & $(0.01)$ & $(0.02)$ \\
& $-0.16^{* *}$ & $-0.05^{* * *}$ & $0.06^{* * *}$ & 0.02 \\
Socio-c. prof. & $(0.05)$ & $(0.01)$ & $(0.01)$ & $(0.05)$ \\
Socio-c. semi-prof. & -0.04 & -0.00 & $-0.09^{* * *}$ & $(0.04)$ \\
& $(0.04)$ & $(0.01)$ & $(0.01)$ & -0.02 \\
Skilled service & 0.02 & 0.01 & 0.01 & $(0.03)$ \\
& $(0.03)$ & $(0.01)$ & $(0.01)$ & 0.03 \\
Unskilled service & 0.01 & 0.00 & 0.01 & $(0.03)$ \\
& $(0.03)$ & $(0.01)$ & $(0.01)$ & $-0.22^{* *}$ \\
& -0.05 & -0.04 & 0.05 & $(0.10)$ \\
\hline Obs & $(0.08)$ & $(0.02)$ & $(0.03)$ & 192207 \\
\hline
\end{tabular}

All models estimated with individual-level controls and country and year FE. Robust standard errors in parentheses. ${ }^{*} p<0.05,{ }^{* *} p<0.01,{ }^{* * *} p<0.001$. 